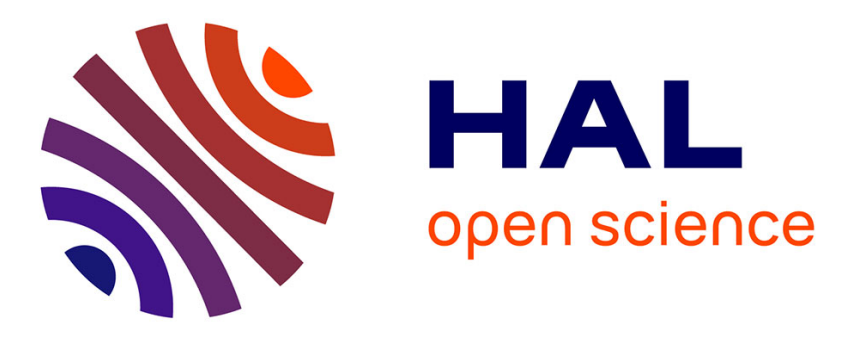

\title{
Quantification and localization of the liquid zone of partially remelted M2 tool steel using X-ray microtomography and scanning electron microscopy
}

G. C. Gu, Raphäl Pesci, Eric Becker, Laurent Langlois, Régis Bigot, Mario Scheel

\section{To cite this version:}

G. C. Gu, Raphaël Pesci, Eric Becker, Laurent Langlois, Régis Bigot, et al.. Quantification and localization of the liquid zone of partially remelted M2 tool steel using X-ray microtomography and scanning electron microscopy. Acta Materialia, 2012, 60 (3), pp.948-957. 10.1016/j.actamat.2011.10.039 . hal-00959514

\section{HAL Id: hal-00959514 https://hal.science/hal-00959514}

Submitted on 14 Mar 2014

HAL is a multi-disciplinary open access archive for the deposit and dissemination of scientific research documents, whether they are published or not. The documents may come from teaching and research institutions in France or abroad, or from public or private research centers.
L'archive ouverte pluridisciplinaire HAL, est destinée au dépôt et à la diffusion de documents scientifiques de niveau recherche, publiés ou non, émanant des établissements d'enseignement et de recherche français ou étrangers, des laboratoires publics ou privés. 


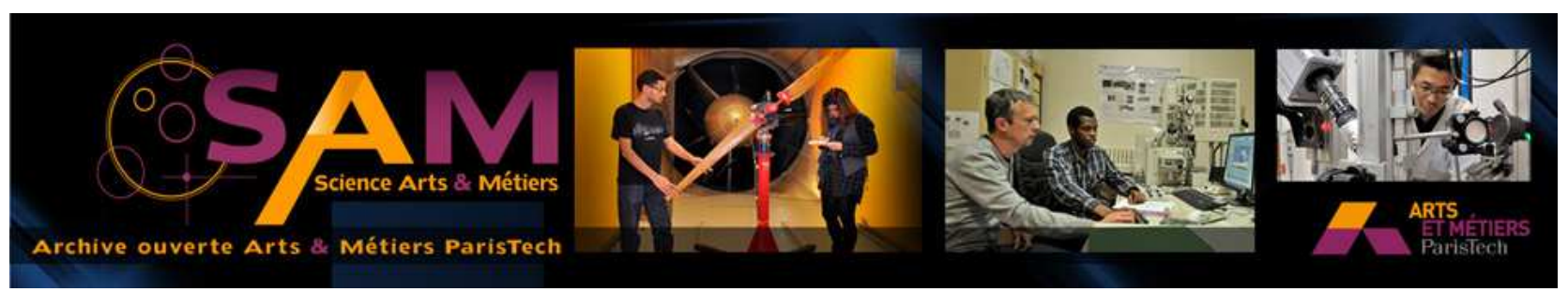

\section{Science Arts \& Métiers (SAM)}

is an open access repository that collects the work of Arts et Métiers ParisTech researchers and makes it freely available over the web where possible.

This is an author-deposited version published in: http://sam.ensam.eu

Handle ID: .http://hdl.handle.net/10985/7857

\section{To cite this version :}

G. C. GU, Raphaël PESCI, Eric BECKER, Laurent LANGLOIS, Régis BIGOT, Mario SCHEEL Quantication and localization of the liquid zone of partially remelted M2 tool steel using X-ray microtomography and scanning electron microscopy - Acta Materialia - Vol. 60, n³, p.948-957 2012 


\title{
Quantification and localization of the liquid zone of partially remelted M2 tool steel using X-ray microtomography and scanning electron microscopy
}

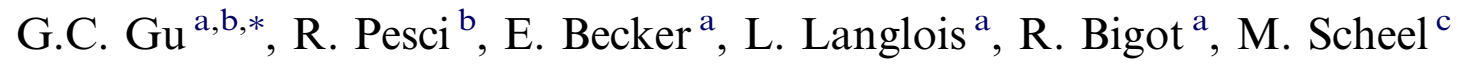

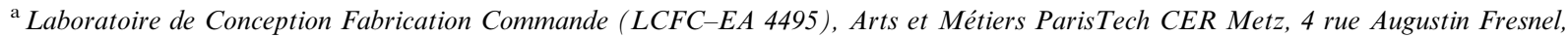 \\ 57078 Metz Cedex 3, France \\ b Laboratoire d'Etude des Microstructures et de Mécanique des Matériaux (LEM3), UMR CNRS 7239, Arts et Métiers ParisTech CER Metz, \\ 4 rue Augustin Fresnel, 57078 Metz Cedex 3, France \\ ${ }^{\mathrm{c}}$ ESRF, ID15 Beamline, 6 rue Jules Horowitz, BP 220, 38043 Grenoble Cedex 9, France
}

\begin{abstract}
Thixoforming of steels poses challenges due to the high temperatures involved and the lack of understanding of thermomechanical behavior. The volume fractions of the liquid and solid phases in the semi-solid state are the most important parameters for such a forming process, as they affect the viscosity and hence the flow behavior of the material. Two-dimensional observations might not always be sufficient, as the size distribution and the connectivity of phases cannot be obtained from associated measurements, which can only be determined by three-dimensional (3-D) investigation. This paper presents the first application of high-energy X-ray microtomography to the microstructure of steel in the semi-solid state. The microstructure of M2 high-speed tool steel was studied in both as-received and heated-and-quenched states. From the reconstructed images, 3-D information could be obtained and was compared with scanning electron microscopy and energy dispersive spectrometry observations. The volume fraction and the location of liquid phase in the semi-solid state were determined in particular, and the continuous solid skeleton was investigated.
\end{abstract}

Keywords: Semi-solid steel forming; Thermomechanical behavior; X-ray microtomography

\section{Introduction}

Semi-solid metal forming processing was first discovered by Flemings and his group at MIT in the 1970s [1]. As complex parts with high mechanical properties can be formed in a single forming operation, the thixoforming process forming at the semi-solid state by reheating the material - has been of great interest to engineers and scientists. Actually, the thixoforming of light alloys such as aluminum alloys has already been industrialized $[2,3]$ and the thixoforming of steels has recently been studied by many researchers and industries as a potential manufacturing technology for industrial components [4,5]. During this process, an appropriate quantity of liquid is required. Fundamental knowledge on the formation, location and volume fraction of liquid during the reheating step is therefore of great importance. In partially liquid metals, the liquid fraction and its location, size and shape are indeed the main concerns because these parameters directly influence the microstructure development [6] and control the rheological behavior [7] and forming process [8].

Only under equilibrium conditions can the volume fraction of liquid in the semi-solid state be given for a certain temperature; in other cases, it depends on the previous thermal history. As for the determination of the volume fraction of 
liquid, various approaches have been applied either by direct definition of the liquid fraction or by means of the effect on special physical properties. Tzimas and Zavaliangos [9] studied three of the methods which are used to determine the volume fraction of liquid as a function of temperature for alloys in the semi-solid state, namely thermal analysis techniques, image analysis of samples quenched from the semi-solid state and thermodynamic data. Meanwhile, the accuracy, advantages and limitations of each method were assessed and recognized. Puttgen and Bleck [10] carried out extensive DTA (differential thermal analysis) experiments at various heating rates to determine the semi-solid area of different steels. The DTA results were combined with subsequent quenched microstructure parameters such as grain size, phase distribution, volume fraction, shape factor, matrix character etc. Omar et al. [11] performed DTA and partial remelting experiments on a high-performance HP9/4/30 steel, which is difficult to manufacture through conventional processes. The results of liquid fraction as a function of temperature obtained by differential thermal analysis and image analysis on the samples quenched from semi-solid were compared and discussed. They observed that liquation occurred initially at grain boundaries, then along the segregation bands. Omar et al. [12] studied the microstructures and phases of as-annealed M2 high-speed tool steel in the as-received condition and in the semi-solid state. The role of carbide dissolution in the grain boundary liquation of the steel was described and led to the production of a microstructure suitable for the thixoforming process. The above-mentioned microstructure observation and liquid fraction calculation were studied on two-dimensional (2-D) metallographic sections obtained after quenching the sample from the semisolid state; the 2-D image analysis may not give a complete image of the structure and can sometimes lead to invalid conclusions. Thus, three-dimensional (3-D) analysis is required. Rowenhorst et al. [13] used serial sectioning to observe the distribution of particle-particle contacts in semi-solid $\mathrm{Sn}-$ $\mathrm{Pb}$ alloys at various liquid fractions. Compared to the serial sectioning, X-ray microtomography, a non-destructive technique, offers a possibility to retrieve 3-D information from a given specimen. Maire et al. [14] presented the feasibility of obtaining the total liquid volume fraction, the volume distribution, the morphology of entrapped liquid and its 3-D location, for aluminium alloy A357 samples quenched from the semi-solid state. Limodin et al. [15] investigated the overall and local microstructural changes occurring during partial remelting of an Al-15.8 wt. \% Cu alloy by in situ X-ray microtomography. However, such experiments have never been performed on steel grades.

The objective of this paper is to show that the 3-D and 2-D investigations of the microstructure of the M2 steel can provide useful information about the thixoforming process regarding the liquid zones in the semi-solid state. In the present work, two different states of M2 steel are investigated: as-received and quenched material from the semisolid state. The instrumental device and the experimental procedure are described and the microstructure evolution after quenching from the semi-solid state is analysed and discussed. By comparing the results obtained by various techniques, the former liquid zones are finally well identified and quantified.

\section{Material and methods}

\subsection{Material}

The M2 high-speed steel used was produced by hot rolling at a temperature of around $1100^{\circ} \mathrm{C}$. After quenching, it was then annealed three times for $1 \mathrm{~h}$ at $540{ }^{\circ} \mathrm{C}$. This steel was selected because it has a reasonably large freezing range (more than $40^{\circ} \mathrm{C}$ ) compared to other steel grades. Moreover, its high content of alloying elements leads to a relatively low solidus temperature and is very important for 3-D observation using X-ray microtomography (phase contrast mode): especially the tungsten and molybdenum elements because of their high difference in X-ray absorption compared to iron. The chemical composition of M2 steel is given in Table 1.

\subsection{Methods}

X-ray microtomography experiments were carried out at room temperature on the high-energy ID15A beamline at the ESRF (European Synchrotron Radiation Facility) in Grenoble, France, where the X-ray energy ranges from 50 to $100 \mathrm{keV}$. For that purpose, a rolled bar $38 \mathrm{~mm}$ in diameter was first induction-heated into the semi-solid state and water-quenched, and then several samples $1.2 \mathrm{~mm}$ in diameter were taken from this bar using electrodischarge machining. In addition, the microstructure characterization in 2-D was performed using an optical microscope and a Jeol 7001FLV scanning electron microscope (SEM). Energy dispersive spectrometry (EDS) analyses were finally done with an Oxford INCA System to study the distribution of the different alloying elements. All samples observed in 2-D were etched using 2\% Nital (2 $\mathrm{ml} \mathrm{HNO}_{3}+98 \mathrm{ml}$ ethanol).

\subsection{Induction heating process}

The rolled bar was induction-heated by a direct remelting route, that is, heating the slugs from the as-received condition directly to semi-solid state. In order to study the microstructure evolution, the M2 slug was partially heated to the semi-solid state: some zones were in the semi-solid state at high temperature while others remained $100 \%$ solid, similar to the as-received state. The temperature of the semi-solid zone was measured by a pyrometer. After $100 \mathrm{~s}$ of heating time, the slug reached $1250{ }^{\circ} \mathrm{C}$

Table 1

Chemical composition of the M2 steel grade.

\begin{tabular}{llllllll}
\hline wt. $\%$ & C & Mn & Mo & Si & Cr & V & W \\
\hline M2 & 0.85 & 0.25 & 5.0 & 0.035 & 4.1 & 1.9 & 6.4 \\
\hline
\end{tabular}




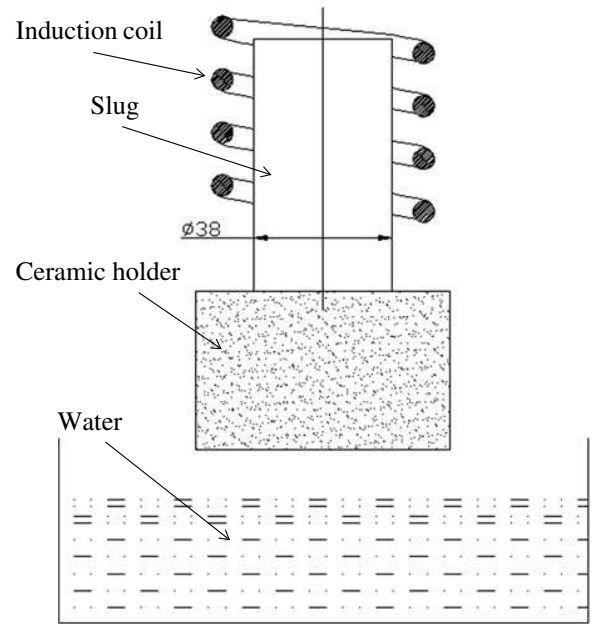

(a)

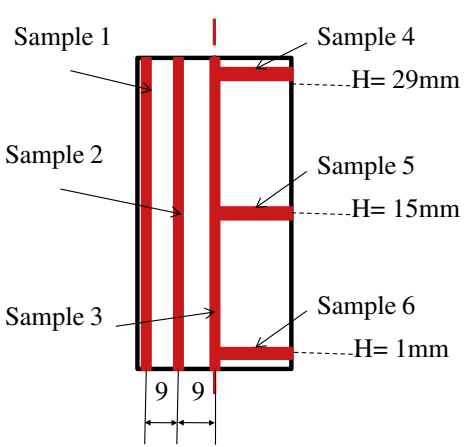

(b)

Fig. 1. Schematic view of (a) the set-up for induction heating experiments and (b) the position of samples for X-ray microtomography.

( $\sim 20 \%$ of liquid phase) and was directly quenched into a water tank without any holding time to freeze the microstructure presented in the semi-solid state and prevent the diffusion of alloy elements in the steel. The schematic view of the set-up for the induction heating experiment is shown in Fig. 1. During the induction heating process, the slug was partially inserted into the induction coil with a part sitting on a ceramic holder, to ensure the coexistence of solid and semi-solid states. As illustrated in Fig. 2, due to the effect of penetration depth, a typical bell-shaped temperature profile was therefore obtained: temperature decreased with decreasing radius and height. The bottom of the slug was slightly colder due to a deficit of heat source in this area: it remained in the solid state during induction heating. Therefore, the temperature in zone B was below the solidus temperature, which will enable us to compare both solid and semi-solid states.

\subsection{X-ray microtomography experiments}

Samples were electrodischarge-machined from the quenched bar for the microtomography experiments. In these experiments, each sample was mounted on translation and rotation stages in order to achieve a good alignment with the X-ray beam before the measurement and a $360^{\circ}$ rotation for $3-\mathrm{D}$ observation. In the tests, a $15 \mu \mathrm{m}$ thick LuAG:Ce scintillator was used to convert the X-ray light into visible light. The incident X-ray beam was directed onto the rotating samples with a constant energy of $60 \mathrm{keV}$. The transmitted beam was recorded using a fast DALSTAR Pantera 1M60 CCD detector, with an exposure time of $\sim 25 \mathrm{~ms}$. The effective pixel size was $\sim 1.2 \mu \mathrm{m}$ and 3600 projections were captured. The slices were then reconstructed and the different volumes obtained were processed and analyzed with the image analysis software, ImageJ.

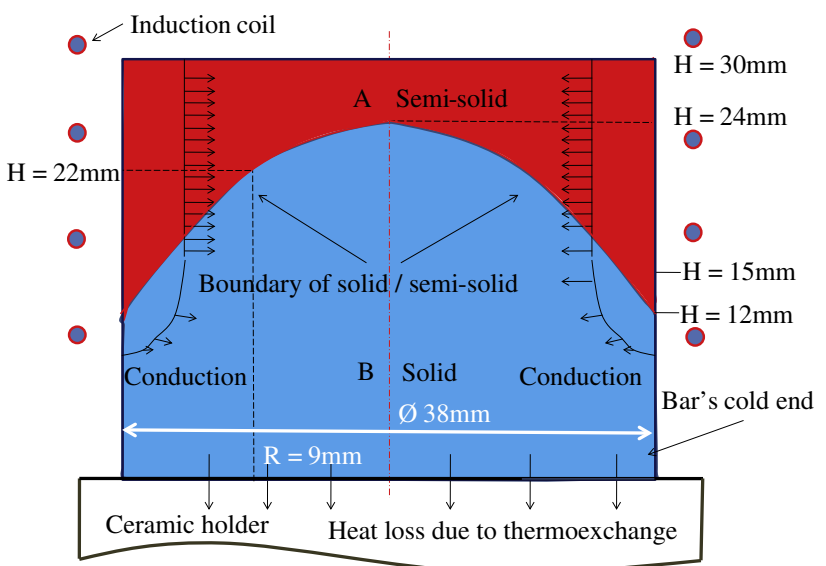

Fig. 2. Schematic view of temperature distribution during induction heating.

\section{Results}

\subsection{Material in the initial state}

The scanning electron micrographs of the as-received M2 high-speed tool steel obtained on transverse and longitudinal sections are presented in Fig. 3a-c. Fig. 3c is a close-up of the area outlined in Fig. 3b. In addition, Fig. 4 illustrates the EDS results of carbides marked in Fig. 3c. The average grain size is $\sim 10 \mu \mathrm{m}$ and the carbide particles are distributed along the grain boundaries and in the matrix. The longitudinal surface (shown in Fig. 3b) bears evidence of microsegregation banding along the longitudinal direction of the slug. Two different types of carbides present in the material were confirmed by EDS analyses (shown in Fig. 4): the whiter particles are $\mathrm{M}_{6} \mathrm{C}$ type carbides, rich in tungsten and molybdenum, while the darker ones are MC-type carbides rich in vanadium, tungsten and molybdenum. Table 2 shows the chemical composition (wt.\%) of these two types of carbides. 

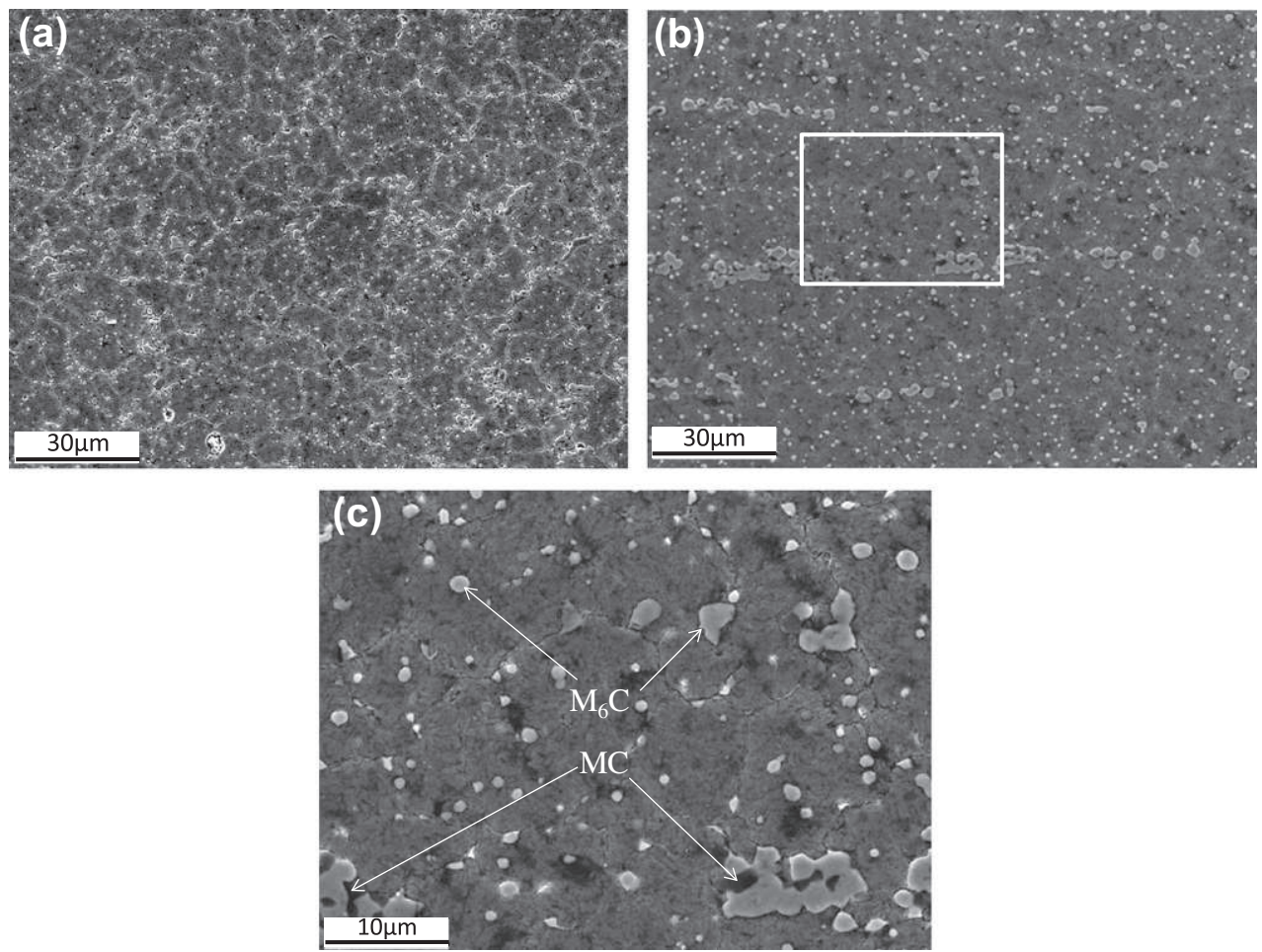

Fig. 3. SEM micrographs of as-received M2 steel on (a) cross-sectional surface and (b) longitudinal surface. (b) Shows the carbide segregation caused by forging. (c) Is a close-up of the area outlined in (b) with two kinds of carbide: $\mathrm{M}_{6} \mathrm{C}$ and MC.
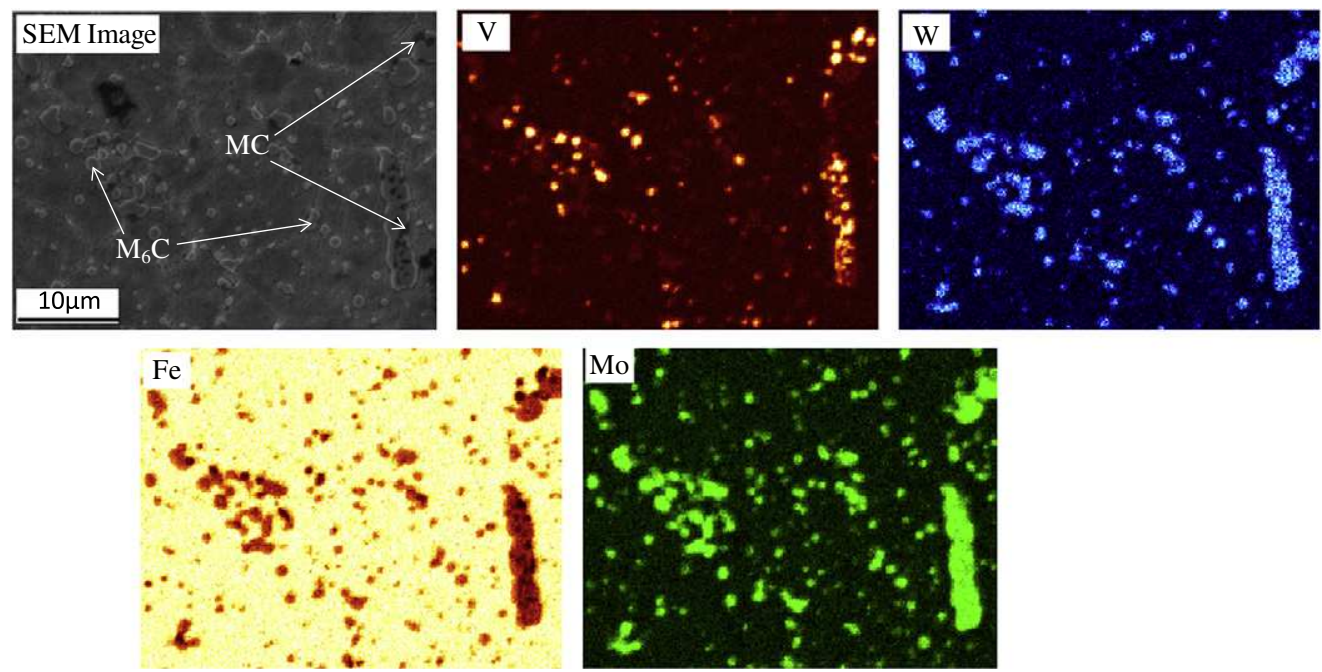

Fig. 4. SEM-EDS mapping of as-received M2 steel.

High-energy X-ray microtomography experiments were also carried out using as-received samples. Thanks to the high content of heavy alloying elements, a good contrast between the matrix and carbides could be obtained. Fig. 5 shows two tomographic slices and a reconstructed stack of a cylindrical sample of as-received M2 steel. The carbide particles are present as white zones in all images; they are relatively small - a few micrometers - and are observed to be either isolated or distributed in bands. This is in good agreement with the SEM and EDS observations.
Table 2

The characteristic chemical compositions of the large and fine carbides.

\begin{tabular}{llllll}
\hline Elements & \multicolumn{5}{l}{ Carbide (wt.\%) } \\
\cline { 2 - 6 } & $\mathrm{V}$ & $\mathrm{Cr}$ & $\mathrm{Fe}$ & $\mathrm{Mo}$ & $\mathrm{W}$ \\
\hline Whiter particles & 3.65 & 2.88 & 30.4 & 24.87 & 38.29 \\
& 2.55 & 3.19 & 34.2 & 22.37 & 37.69 \\
& 3.05 & 3.04 & 32.22 & 25.35 & 36.34 \\
Darker particles & 34.72 & 4.76 & 9.3 & 23.98 & 27.25 \\
& 32.7 & 4.61 & 10.43 & 23.67 & 28.6 \\
& 35.32 & 5.06 & 10.06 & 20.72 & 28.88 \\
\hline
\end{tabular}



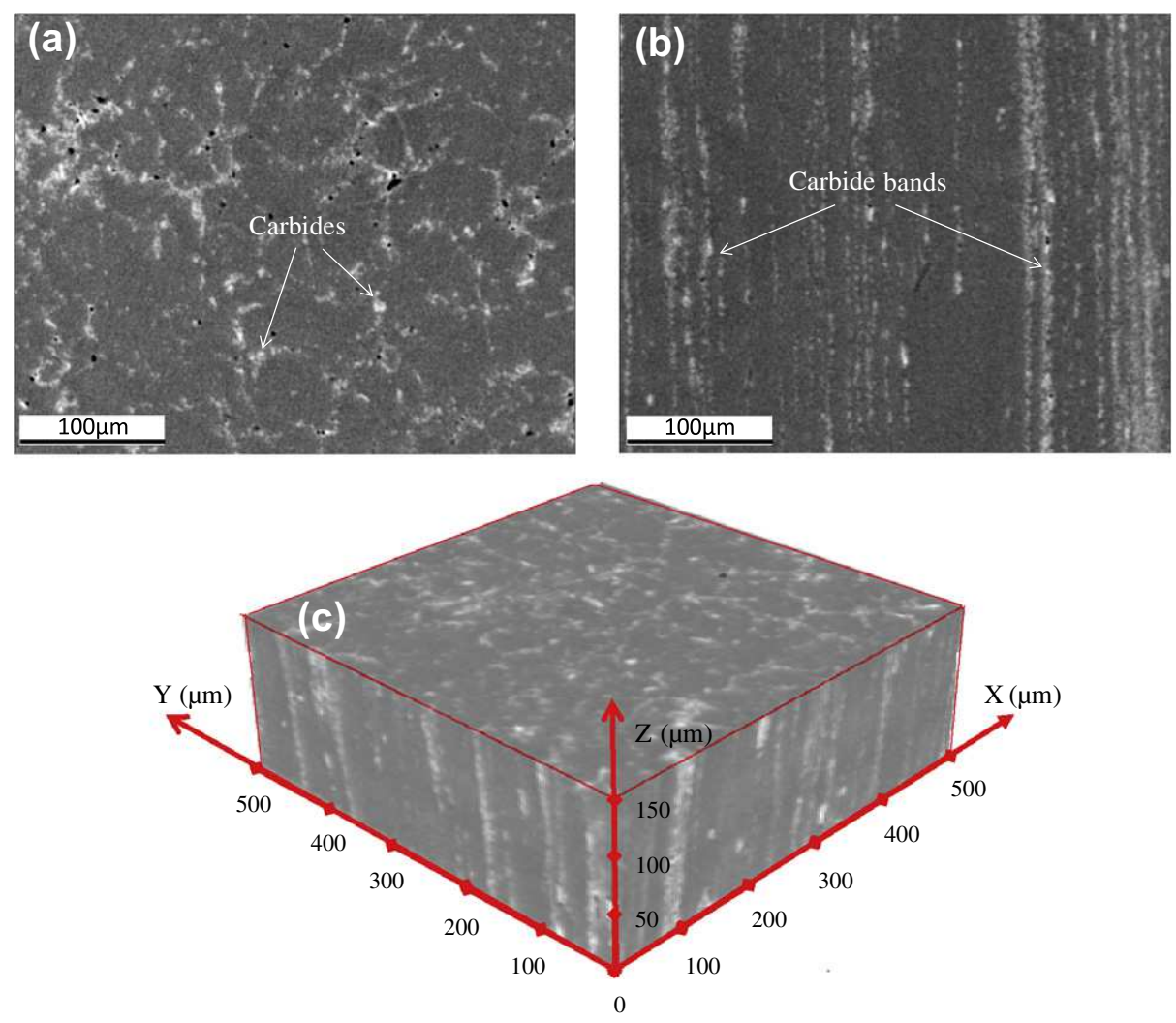

Fig. 5. X-ray microtomographic results of as-received M2 steel. Carbides are shown as white zones in (a) transverse section, (b) longitudinal section and (c) reconstructed 3-D stack.

\subsection{Microstructure of material quenched from the semi-solid state}

Once directly induction-heated from its as-received state to the semi-solid state, the slug was then quenched to freeze the microstructure present in the semi-solid state. Micrographs of the quenched slug are shown in Fig. 6.

It is observed that M2 now exhibits equiaxed grains $40 \mu \mathrm{m}$ in average grain size on the transverse section, and elongated grains on the longitudinal section with an average grain size of $40 \mu \mathrm{m} \times 65 \mu \mathrm{m}$. One can also note that grain boundaries in transverse section and new carbides along grain boundaries in longitudinal section can form some interconnected networks. Two kinds of carbides with a high content of tungsten, molybdenum and vanadium surrounding the grains were detected by EDS analyses (Fig. 7): large MC-type carbides which are rich in tungsten, molybdenum and vanadium, as well as finer tungstenmolybdenum-rich $\mathrm{M}_{6} \mathrm{C}$-type carbides. There were no such elements remaining inside the grains compared to the asreceived state: they were now concentrated in the grain boundaries. The microstructure differs from the one in the as-received state in grain size, distribution of carbides and morphology.

X-ray microtomography images were successively recorded in parallel after quenching at room temperature. Two reconstructed slices representing the transverse and longitudinal sections of partial remelted sample are presented in Fig. 8a and b, respectively. When compared to the SEM micrographs, the similarities of the structures
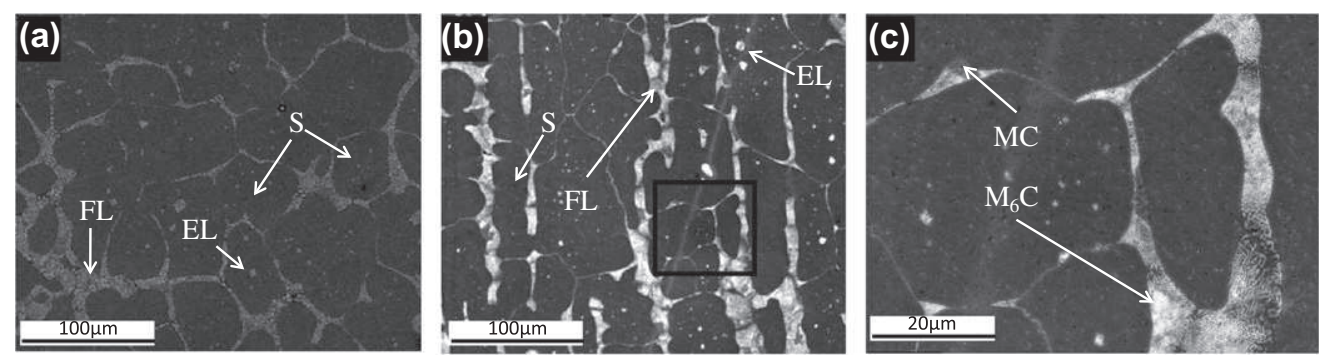

Fig. 6. SEM micrographs of the M2 steel quenched from semi-solid state. (a) Transverse and (b) longitudinal directions. (c) Is a close-up of the area outlined in (b) and shows two kinds of carbide. FL: former liquid phase; EL: entrapped liquid; S: solid phase. 

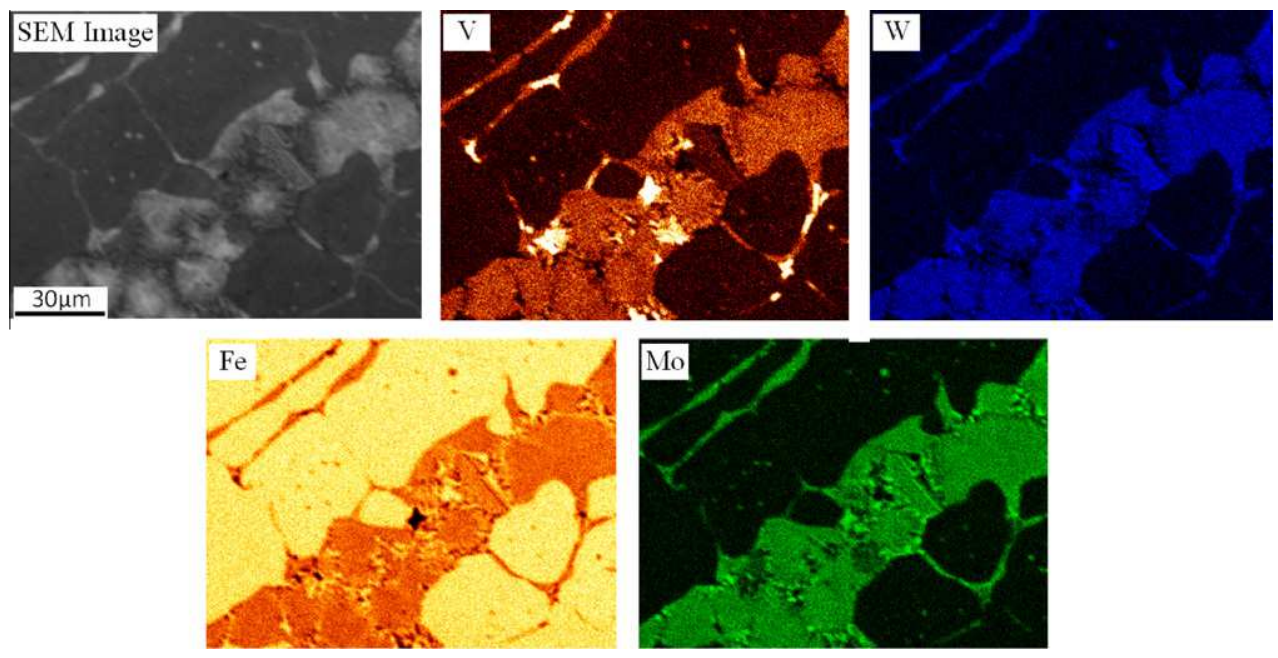

Fig. 7. SEM-EDS mapping of the M2 quenched from the semi-solid state.
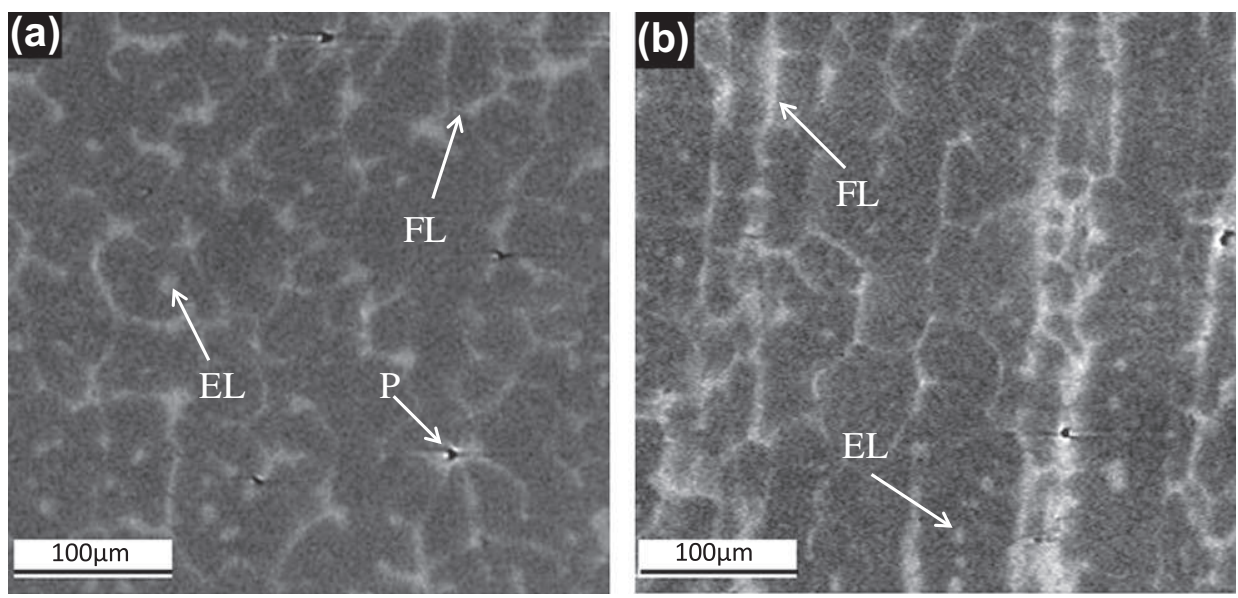

Fig. 8. 2-D reconstructions of partial remelted and quenched sample 1. (a) Transverse and (b) longitudinal sections. FL: former liquid phase; EL: entrapped liquid; P: porosity.

are very clear. It is well observed that the material evolves dramatically during partial remelting. Compared to the original carbide particles, the morphology of these reformed carbides is different in both their dimensions and localization. During induction heating, as the temperature rises, alloying elements, such as vanadium, tungsten and molybdenum among others, diffuse to the liquid zones where the solubility is higher. These liquid zones, preferably developing from the grain boundaries, appear very clearly after quenching because of their high content in alloying elements. They form new interconnected carbide networks that make the definition of the new grain size obvious. It can be conjectured that M2 steel exhibits a microstructure combining both solid and liquid phases before quenching.

As the agreement between 2-D SEM observations and $\mathrm{X}$-ray microtomography results is good, the real volume fraction of liquid can be obtained by the image analyses on reconstructed stacks as shown in Fig. 9; the connected carbide networks are white zones.
With the image processing software ImageJ, the total volume fraction of carbides as a function of height and diameter of samples taken from the initial slug are shown in Fig. 10. First, it can be seen that the fraction of carbides increases with height and radius, Fig. 10a and b, but at different rates. As illustrated in Fig. 10a, for sample 1, this fraction remains stable from the bottom up to the height of $12 \mathrm{~mm}$, around $11 \pm 1 \%$. Then, it grows rapidly from $11 \pm 1 \%$ to $15 \pm 1 \%$ from $12 \mathrm{~mm}$ to $17 \mathrm{~mm}$ in height, and seems to remain constant until $24 \mathrm{~mm}$ in height. Finally, it increases until reaching the value of $21 \pm 1 \%$. The evolution of carbide fraction in sample 2 and in sample 3 is quite similar to that of sample 1 , but with a discrepancy of $\sim 10 \mathrm{~mm}$ and $14 \mathrm{~mm}$ in height, respectively. The expected bell-shaped profile is here confirmed. Moreover, at the same height $(>23 \mathrm{~mm})$, the fractions of carbides in sample 3 are smaller than those in sample 2 by $2 \%$. In Fig. 10b, the fraction in sample 4 increases with radius, while the one of sample 6 remains relatively constant. For sample 5, it increases to $14 \pm 1 \%$ after remaining at 


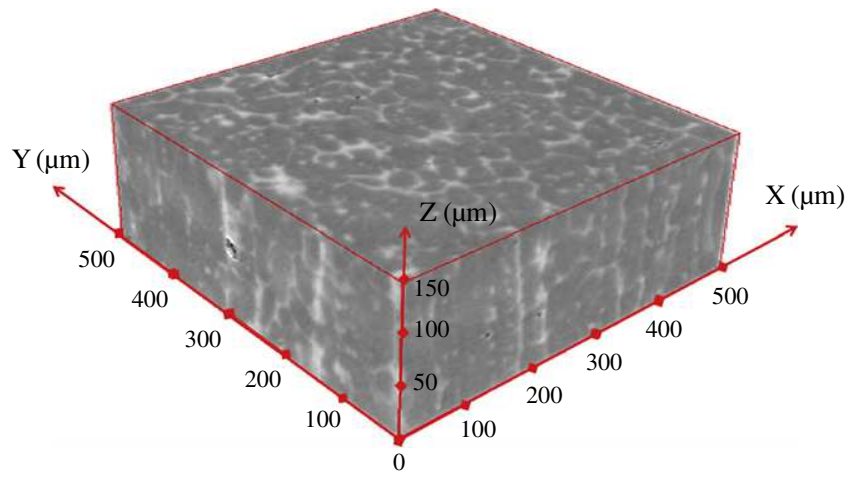

Fig. 9. 3-D representation of M2 steel in partial remelted and quenched state. Volume $=0.6 \mathrm{~mm} \times 0.6 \mathrm{~mm} \times 0.16 \mathrm{~mm}$.
$11 \pm 1 \%$ from the core until the radius of $11 \mathrm{~mm}$. In addition, for the same radius, the fraction of carbides increases with height in these three samples.

Furthermore, as illustrated in Fig. 10a, the zones with a fraction of carbides of $11 \pm 1 \%$ in samples 1,2 and 3 exhibit the kind of carbides seen in Fig. 3, while the ones with a fraction of carbides more than $13 \pm 1 \%$ show the newly formed carbides during quenching from liquid state as presented in Fig. 6. Finally, initial carbides and new ones coexist in the zones with a fraction of carbides between $11 \pm 1 \%$ and $13 \pm 1 \%$.

The microstructures of sample 1 at different heights are presented in Fig. 11. Figures marked with an S are SEM micrographs while the ones marked with a $\mathrm{T}$ come from $\mathrm{X}$-ray microtomography images. As shown in these images,

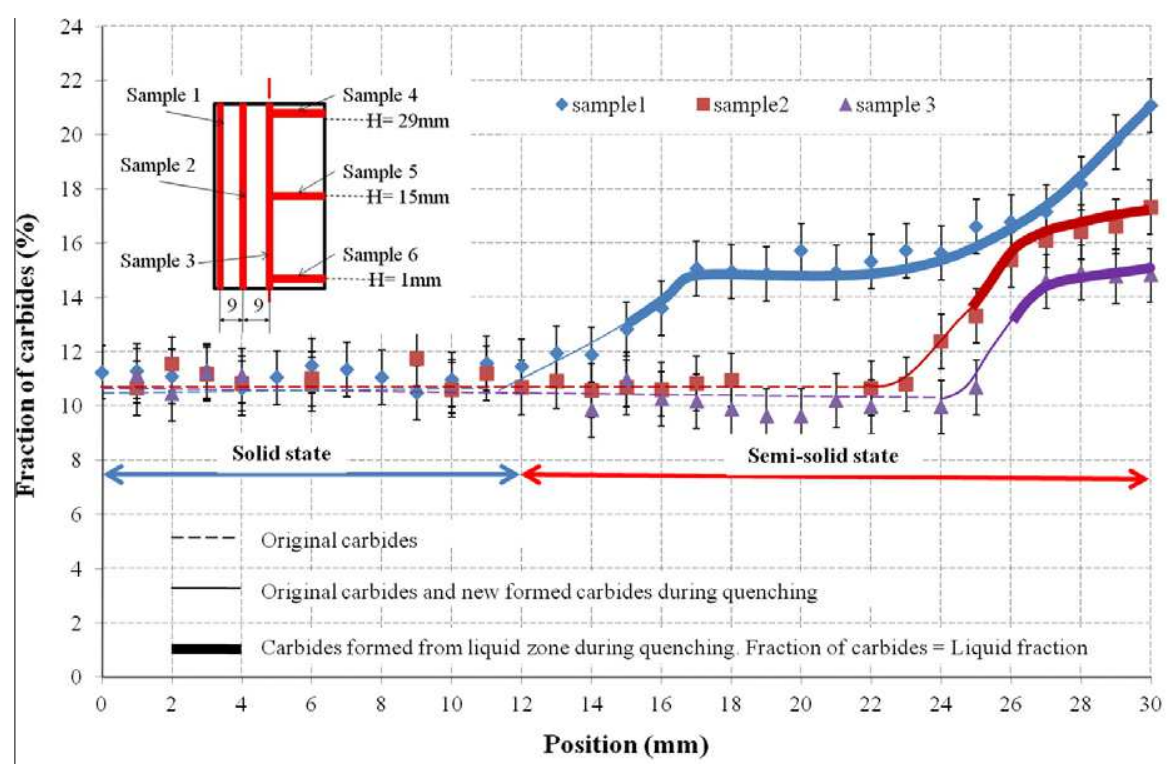

(a) Axial direction

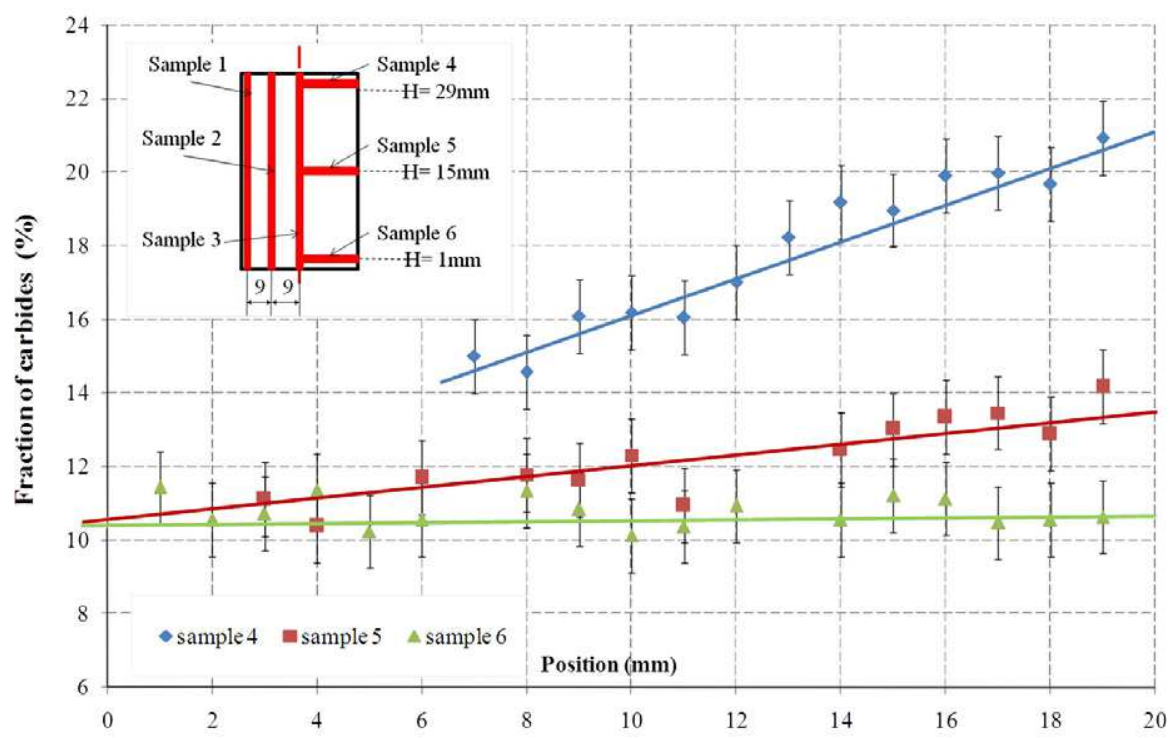

(b) Radial direction

Fig. 10. Volume fraction of liquid as a function of the height of partial remelted and quenched M2 steel. 


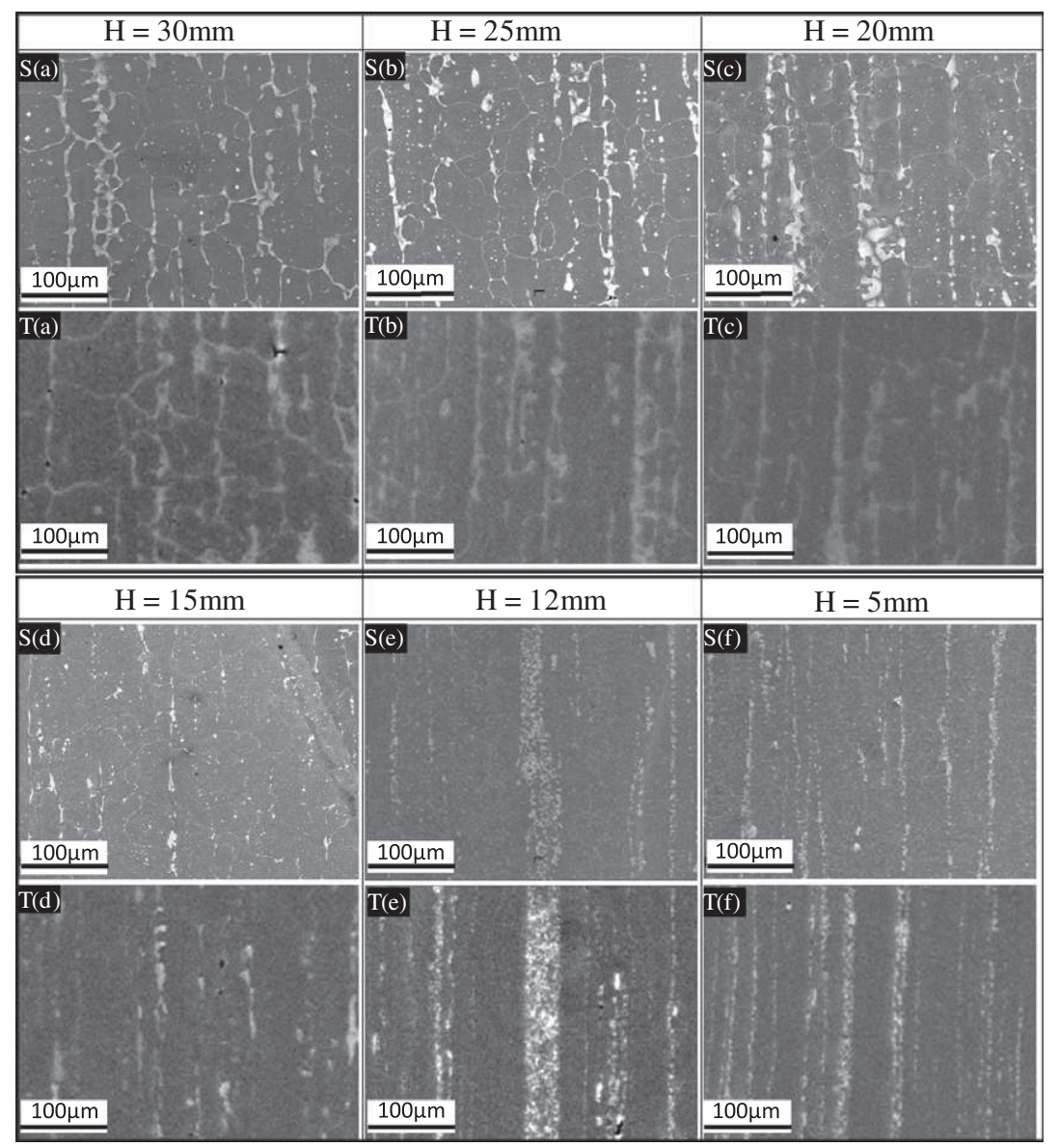

Fig. 11. SEM micrographs and X-ray microtomography slices observed at different heights in sample 1 .

the microstructure changes in grain size and morphology depending on the standoff distance. The greater the height, the higher the temperature. At $5 \mathrm{~mm}$ from the bottom, the obtained microstructure is similar to the one observed in the as-received material: the majority of the carbide particles have the same dimensions and are still distributed in the matrix and bands.

With increasing temperature, most of the original carbide particles are dissolved and the alloying elements in carbides along the microsegregation bands start diffusing to the liquid zones; new carbides are being created at the grain boundaries after quenching, as illustrated by the microstructure at the height of $15 \mathrm{~mm}$. At the same time, the grains are growing. Then, higher in the sample, for instance at the height of $20 \mathrm{~mm}$, the process is enhanced with the development of still larger interconnected liquid zones and grains. Finally, at the heights of $25 \mathrm{~mm}$ and $30 \mathrm{~mm}$, the original carbides are completely dissolved, with the diffusion of the alloying elements to the liquid zones, forming very large new carbides after quenching because the fraction of liquid is $\sim 21 \%$. Small carbides can also be present inside the grains, corresponding to the entrapped liquid zones at high temperature which represent $\sim 7 \%$ of total liquid, using image analysis. In addition, the SEM micrographs and X-ray microtomography results are in quite good agreement, when taking into account the resolution of the two techniques.

\section{Discussion}

In this study, two states of M2 steel have been investigated: as-received state and quenched from the semi-solid state.

\subsection{Material in the as-received state}

Concerning the initial as-received state, microsegregation bands parallel to the rolling direction are observed. They are typical for most commercially produced highspeed tool steels such as M2 grade, which contain a high amount of slowly diffusing elements [11]. When comparing the SEM micrographs (Fig. 3) and X-ray microtomography slices (Fig. 5), the correspondence is good; some very small differences in grain size and carbide distribution can be observed, which may result from the $3 \mu \mathrm{m}$ resolution of X-ray microtomography. As seen in Fig. 3, the size of many carbide particles is smaller than $1 \mu \mathrm{m}$, which makes them impossible to distinguish with the lower resolution of X-ray microtomography. Moreover, when the distance between several isolated carbide particles is less 
than $3 \mu \mathrm{m}$, they will probably be considered only as one large particle. In any case, the global isolated carbide particles and the segregation bands can be observed in the X-ray microtomography results. With ImageJ, the volume fraction of carbides in the as-received state is $11 \pm 1 \%$, with a relatively homogeneous distribution.

\subsection{Material in semi-solid state after quenching}

In the micrographic study of M2 steel, the partially remelted and quenched material exhibits a microstructure that is different from the as-received material in morphology, grain size and carbide distribution. The grains are $40 \mu \mathrm{m}$ in size compared to $10 \mu \mathrm{m}$ in the as-received state, and surrounded with large carbides which correspond to the former liquid zones at high temperature, as shown in Fig. 6. Puttgen et al. [16] stated that with longer holding times, the average diameter of the grain increases steadily due to the ripening process, which results in a decreasing contiguity at high temperature. It is also found that a rise in partial remelting temperature will increase the grain sphericity level for AISI M2 [12] and for XW-42 [17]. In the present study, we have mainly focused on the semi-solid with a low volume fraction of liquid $\left(F_{1}<20 \%\right)$. The shape of grains is not perfectly spherical due to the high heating rate and the absence of holding time.

As shown in Fig. 2, the typical bell-shaped temperature profile marks the boundary between the semi-solid zone (zone A) and pure solid ones (zone B). Thereby the initial carbides are shown in zone B with a fraction of $11 \pm 1 \%$. When they reach the solidus temperature, alloying elements in the original carbide $\mathrm{MC}$ first diffuse into the liquid zone and form large new carbides when quenched as presented in Fig. 12: microstructure of sample 1 at the height of $14 \mathrm{~mm}$. With increasing temperature above the melting point of $\mathrm{M}_{6} \mathrm{C}$, all original carbides at the grain boundary are dissolved and new carbides are created during the following quenching process as shown in Fig. 11S(d). As the temperature increases with height, the diffusion process is

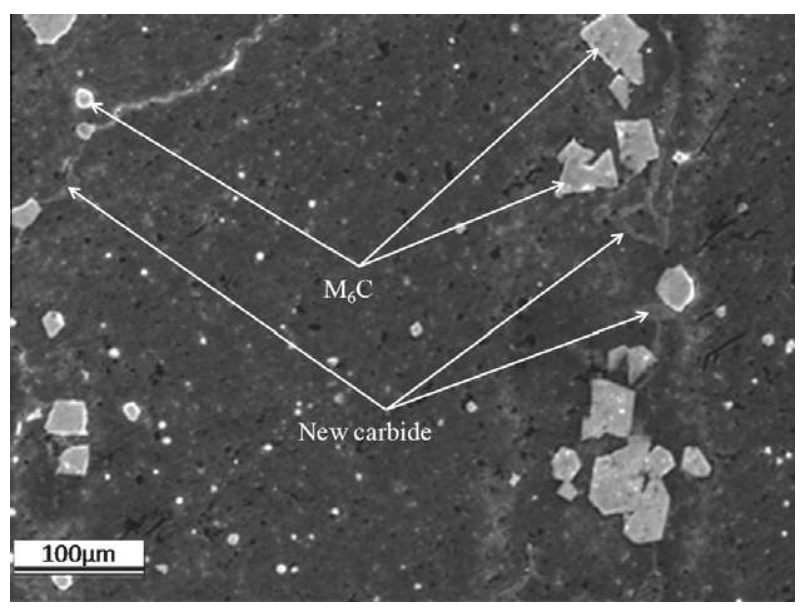

Fig. 12. Microstructure of sample 1 at the height of $14 \mathrm{~mm}$. enhanced with the development of interconnected liquid zones in higher positions. Small carbides are also observed inside the grains, corresponding to the entrapped liquid zones at high temperature. This is due to the high heating speed and the short holding time that prevent all the alloying elements from diffusing completely to the liquid zones. Here, due to the resolution of X-ray tomography, few carbides allocated in grains are detected when comparing the images presented in Fig. 11 obtained by two techniques. Thus, based on the X-ray microtomography results, the fraction of carbides over $13 \pm 1 \%$ is considered to be the real liquid fraction.

Since sample 6 was taken from zone B (solid state), the fraction of carbides is relatively constant, which means that the distribution of original carbides is homogeneous. Indeed, the temperature distribution in the radial direction is similar to that in the axial direction: temperature increases with increasing radius, the evolution of microstructure in the radial direction is similar to that in the axial direction. Fractions of carbides of sample 4 and 5 in zone A (semi-solid state) increase with the radius, with higher values on the surface than in the core of the slug. Meanwhile, temperature is also height-dependent: the higher the position, the higher the temperature. For the same position, fractions of carbides of different samples are compared in Table 3. By comparing these values, the axisymmetrical temperature field in the heated bar is confirmed.

When comparing the grain size at various heights, it is noted that the grains stop growing when large connected liquid bands are formed, which may be related to the carbide pinning of grain boundaries [12]. There is a significant grain growth during reheating when comparing the grain size of the as-received state and of quenched from the semi-solid state. In general, the grain grows with increasing temperature and holding time. It is important to study the grain growth during reheating, as large grains cannot flow into thin sections as easily as those of a finer size. Furthermore, the mechanical properties of the part will be weakened if the grain size is larger. One explanation for the grain growth was proposed by Omar et al. [18]: the grain growth and diffusion process are thermally activated. They are also related to the liquid fraction, because liquid provides a much faster diffusion path than solid, and once a continuous liquid path is present around the solid phase, coarsening can accelerate, which results in the grain growth. In addition, grain coalescence is also thought to be an important factor to the grain growth, as stated by Tzimas and Zavaliangos [19].

The obtained microstructure at high temperature is not exactly the most typical one for thixoforming - solid spherical grains surrounded by a liquid matrix - but the semisolid zone with a liquid fraction ranging from $16 \%$ to $20 \%$ interconnected at the grain boundaries makes it suitable for thixoforming, as discussed below.

First, although there is a significant grain growth from the as-received state, the grains are relatively equiaxial with a final grain size around only $40 \mu \mathrm{m}$. Then, the billet 
Table 3

Fractions of carbides in various positions.

\begin{tabular}{|c|c|c|c|c|c|c|c|}
\hline \multirow[t]{2}{*}{ Height (mm) } & \multirow[t]{2}{*}{ Radius (mm) } & \multicolumn{6}{|c|}{ Fraction of carbides $(\%)$} \\
\hline & & Sample 1 & Sample 2 & Sample 3 & Sample 4 & Sample 5 & Sample 6 \\
\hline 29 & 18 & 19.7 & & & 19.6 & & \\
\hline 29 & 9 & & 16.62 & & 16.11 & & \\
\hline 15 & 18 & 12.83 & & & & 12.90 & \\
\hline 15 & 9 & & 10.97 & & & 11.66 & \\
\hline 15 & 1 & & & 10.89 & & 10.45 & \\
\hline 1 & 18 & 11.3 & & & & & 10.56 \\
\hline 1 & 9 & & 11.54 & & & & 10.94 \\
\hline 1 & 1 & & & 11.11 & & & 10.64 \\
\hline
\end{tabular}

contains low liquid fraction in the semi-solid zone (15-25\%) mainly developed from the grain boundaries. The advantages of such a microstructure have been introduced in Ref. [20]. Some M2 [21] and C38 [22] steels have been successfully thixoformed with such a liquid fraction. Finally, as shown in Fig. 11S(d), the microstructure at a height of $15 \mathrm{~mm}$ in sample 1 exhibits thin liquid films formed at grain boundaries, which may not be sufficient for grains to flow freely against each other. With the increasing height, the temperature increases too. The liquid films thicken with increasing temperature, as shown in Fig. $11 \mathrm{~S}(\mathrm{a})$ and $\mathrm{S}(\mathrm{b})$. They will result in a reduction of solid skeleton consistency, which may be easier to fracture during thixoforming. Thus, these microstructures might behave in a thixotropic way, flowing when stressed and thickening under normal conditions. In our future work, it will be necessary to study the load-displacement curves of thixoforging process in order to better understand the relationship between the microstructure and the behaviour of the steel.

\section{Conclusion}

After being induction-heated and water-quenched, the microstructure evolution of an M2 steel was monitored and examined with various 2-D and 3-D techniques. While the as-received material showed microsegregation bands in longitudinal section and homogeneously distributed small carbides in transverse section, with MC-type and $\mathrm{M}_{6} \mathrm{C}$-type carbides identified by EDS analyses, the partially remelted material exhibited a different microstructure. The grains were bigger, and the solid phase was surrounded with the new large carbides formed during quenching, which corresponded to the former liquid zones at high temperature. During heating, most of the liquid appeared in the microsegregation bands that can form interconnected networks. All this leads to the conclusion that the microstructures obtained at high temperature are suited to the thixoforming process, owing to the good liquid fraction (15-20\%) and the interconnected networks.

Furthermore, the good agreement between 2-D SEMEDS microstructures and 3-D X-ray microtomography results proves that both kinds of techniques are just as efficient in characterizing high-alloyed steels in the semi-solid state. This last point is of great importance because even though high-energy X-ray microtomography has proven to be a powerful tool, it is not as easy to use, nor as ubiquitous, as SEM and EDS techniques that are more readily accessible in laboratories and actually just as well-adapted for this kind of analysis.

\section{Acknowledgements}

The authors warmly thank Luc Morhain and Marc Wary (Arts et Métiers ParisTech CER Metz) for their technical support.

\section{References}

[1] Spencer DB, Mehrabian R, Flemings MC. J Metall Trans 1972;3:25.

[2] Hirt G, Cremer R, Witulski T, Tinius HC. Mater Des 1997;18:315.

[3] Chino Y, Kobata M, Iwasaki H, Mmabuchi M. Acta Mater 2003;51:3309.

[4] Rassili A, Atkinson HV. J Trans Nonferr Met Soc China 2010;20:s1048.

[5] Becker E, Bigot R, Langlois L. Int J Adv Manuf Tech 2010;48:913.

[6] Amin-Ahmadi B, Aashuri H. Mater Process Technol 2010;210:1632.

[7] Bigot R, Favier V, Rouff C. Mater Process Technol 2005;160:53.

[8] Becker E, Favier V, Bigot R, Cezard P, Langlois L. Mater Process Technol 2010;210:1492.

[9] Tzimas E, Zavaliangos A. Mater Sci 2000;33:5319.

[10] Puttgen W, Bleck W. Steel Res Int 2004;75:531.

[11] Omar MZ, Palmiere EJ, Howe AA, Atkinson HV, Kapranos P. Mater Sci Eng A 2005;395:53.

[12] Omar MZ, Atkinson HV, Howe AA, Palmiere EJ, Kapranos P, Ghazali MJ. Mater Sci 2009;44:869.

[13] Rowenhorst DJ, Kuang JP, Thornton K, Voorhees PW. Acta Mater 2006;54:2027.

[14] Maire E, Buffière JY, Salvo L, Blandin JJ, Létang JM. Adv Eng Mater 2000;3:539.

[15] Limodin N, Salvo L, Suéry M, Di Michiel M. J Acta Mater 2007;55:3177.

[16] Puttgen W, Bleck W, Seidl I, Kopp R, Bertrand C. Adv Eng Mater $2005 ; 8: 726$

[17] Alfan A, Omar MZ, Syarif J, Sajuri Z. J Appl Sci 2010;13:55.

[18] Omar MZ, Atkinson HV, Palmiere EJ, Howe AA, Kapranos P. Steel Res Int 2004;75:552.

[19] Tzimas E, Zavaliangos A. Mater Sci Eng 2000;A289:228.

[20] Kirkwood DH. Int Mater Rev 1994;39:173.

[21] Kapranos P, Kirkwood DH, Sellars CM. J Phys IV 1993;3:835.

[22] Becker E, Bigot R, Langlois L, Favier V, Pierret JC, Cezard P. Int J Mater Form 2008;1:977. 